
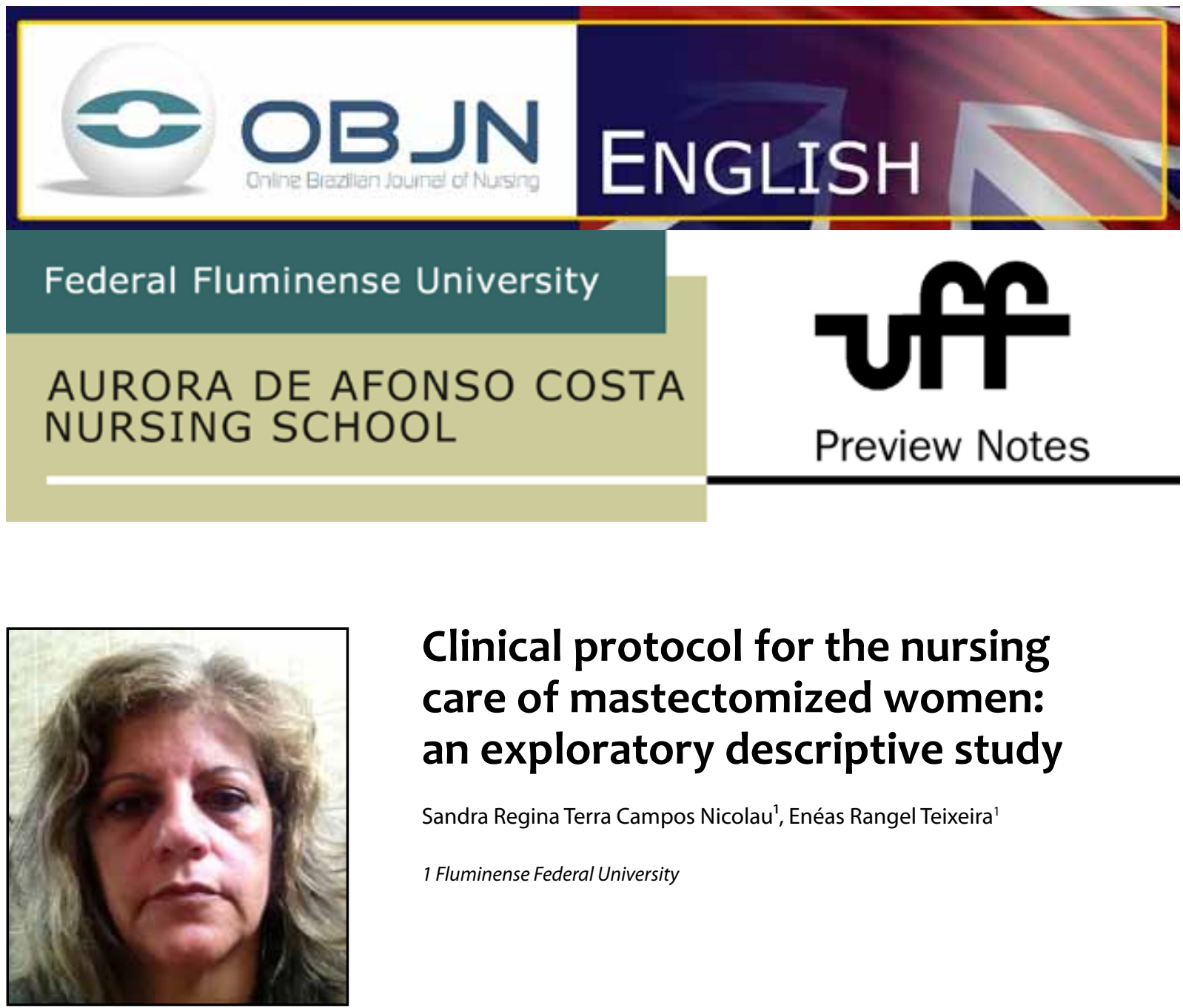

\title{
Clinical protocol for the nursing care of mastectomized women: an exploratory descriptive study
}

\author{
Sandra Regina Terra Campos Nicolau', Enéas Rangel Teixeira' \\ 1 Fluminense Federal University
}

\section{ABSTRACT}

Aims: To describe the nursing care provided to women undergoing mastectomy; to discuss the results in terms of ethical and aesthetic health care and to prepare a supportive clinical protocol aimed at subject autonomy in health care. Method: This is a descriptive and exploratory study, in which a qualitative approach is used. The techniques for data collection will be semi-structured interviews and field observation. Subject: the nursing staff of a female surgical clinic. The scenario will be a ward of the Female Surgical Clinic (FSC) of a university hospital in the federal public educational system in Niterói. The type of analysis will be thematic content. Expected results: This study is a relevant contribution to humane and effective care practice and to the development of knowledge in the area of women's health in oncological nursing. We also expect to contribute to education, research and innovation in care.

Descriptors: Breast Neoplasms; Mastectomy; Nursing Care. 


\section{PROBLEM SITUATION AND ITS SIGNIFICANCE}

In 2014, it is estimated that 57,120 new cases of breast cancer will arise in Brazil(1). This fact requires preventive and curative measures as well as the need for humane care, which is a key to the transformation of the negative representations of professionals, and includes the ethical and aesthetic dimensions. In this sense, we can classify as fundamental: building and sustaining facilities to enable communication; facilitating the dynamics of dialogue, respect and diversity; and the promotion of a dynamic flow of proposed decisions guided by improved humane and supportive relationships between professionals and patients.

The object of study is the pre- and postoperative nursing care aimed at women undergoing mastectomy.

\section{GUIDING QUESTIONS}

- How does the nursing staff take care of mastectomized women?

-What are the nursing interventions focused on the ethical and aesthetic dimensions ${ }^{(2)}$ of women suffering from breast cancer?

- How can we create a protocol for the comprehensive care of mastectomized women, based on the survey?

\section{AIMS}

General Aim: To know how the nursing staff care for women with mastectomies, and from there, create a clinical protocol ${ }^{(3)}$.
Specific aims:

- To describe the nursing care provided to women undergoing mastectomy;

- To discuss the results from an ethical and aesthetic care perspective.

\section{ASSUMPTIONS}

Nursing care provided in a welcoming way, considering the aesthetic and ethical dimensions along with technique, favors the restoration of women undergoing mastectomies who present physical and psychological vulnerability during this process.

\section{METHOD}

The research will be descriptive and exploratory and a qualitative approach will be used.

The scenario will be the gynecological ward of a university hospital in the federal public educational system in Niterói, which usually carries out four mastectomy surgeries per week. Data collection will occur between March and September 2014. The subjects will be the nursing staff of the referred ward. Twenty employees work in this clinic including six nurses on duty, a coordinator on day shift and thirteen technicians and nursing assistants.

Inclusion criteria: nurses, nursing assistants and technicians who have worked for more than six months in the sector and agree to participate in the project. Exclusion criteria: nursing professionals who work shifts but are not part of the female surgical clinic team such as shifts and overtime, but are not part of the female surgical clinic. 
The research instrument is a semi-structured interview, which will allow the collection of demographic data and narratives of the experiences of the interviewee. The script of the interview or observation is prepared in advance, and will guide data collection. The interviews combine open and closed questions, with the respondents having the possibility to interact on the issue without settling on rigid questions and answers. The guide consists of a significant number of questions posed to people, aiming at developing knowledge of the opinions, beliefs, feelings, interests, expectations and situations experienced by the interviewees. The interviews will be recorded for later transcription and analysis in terms of thematic content. If necessary, field observation will be performed to verify the care provided to patients.

The study meets the requirements of Resolution 466/2012 of the National Board of Health and the ethical precepts, thereby protecting the participating subjects. The names of the respondents will be preserved and will be replaced by pseudonyms or codes. All material (digital and printed) will be archived for a period of five years and subsequently incinerated.

The study was approved under opinion number 531,887 by the Research Ethics Committee of the Hospital in which the research will take place.

\section{EXPECTED RESULTS}

The research aims to contribute to nursing care and education, so that the outcomes will focus on the care of women with mastectomies.
From the results of this project, a welfare protocol of care for women who have undergone mastectomy will be prepared. This must accord with the sensitive and human dimension that values life through the ethical and aesthetic paradigms of the subjects, in terms of the actions of the nursing staff. This product will be the result of this project.

We aim to promote life care and quality improvement in nursing care, as well as improving the continuing education and training of nursing staff.

\section{REFERENCES}

1. Instituto Nacional de Câncer José Alencar Gomes da Silva (Brasil). Estimativa 2014 - Incidência do câncer no Brasil [internet] Rio de Janeiro: INCA; 2014. [cited 2014 Sep 01] Available from: http://www.inca.gov.br/estimativa/2014/ sintese-de-resultadoscomentarios.asp

2. Moura FMJSP, Silva MG, Oliveira SC, Moura LJSP. Os sentimentos das mulheres pós-mastectomizadas. Esc Anna Nery Rev Enferm [internet]. $2010 \mathrm{Jul} /$ Set [cited 2013 Jan 21 ];14(3):477-84. Available from: http://www.scielo.br/pdf/ean/ v14n3/v14n3a07.pdf

3. Teston EF, Costa MAR, Baldissera VDA, Marcon SS. Educational views and practices of medical and nursing professionals: a descriptive study. Online Braz J Nurs [internet]. 2013 Dec [cited 2014 Mar 15];12(4). Available from:http:// www.objnursing.uff.br/index.php/nursing/ article/view/4133/pdf_42. DOI: http://dx.doi. org/10.5935/1676-4285.20134133

Project data: Dissertation project of the Professional Master's Degree Program in Nursing Care, Fluminense Federal University. Approved in the Research Ethics Committee of the FFU under number 531,887 .

Advisor: Enéas Rangel Teixeira

Financial support: None 
All authors participated in the phases of this publication in one or more of the following steps, in According to the recommendations of the International Committee of Medical Journal Editors (ICMJE, 2013): (a) substantial involvement in the planning or preparation of the manuscript or in the collection, analysis or interpretation of data; (b) preparation of the manuscript or conducting critical revision of intellectual content; (c) approval of the versión submitted of this manuscript. All authors declare for the appropriate purposes that the responsibilities related to all aspects of the manuscript submitted to OBJN are yours. They ensure that issues related to the accuracy or integrity of any part of the article were properly investigated and resolved. Therefore, they exempt the OBJN of any participation whatsoever in any imbroglios concerning the content under consideration. All authors declare that they have no conflict of interest of financial or personal nature concerning this manuscript which may influence the writing and/or interpretation of the findings. This statement has been digitally signed by all authors as recommended by the ICMJE, whose model is available in http://www. objnursing.uff.br/normas/DUDE_eng_13-06-2013.pdf

Received: 06/02/2014

Revised: 09/09/2014

Approved: 09/09/2014 